\title{
Implantation of Sinoatrial Node Cells Into Canine Right Ventricle: Biological Pacing Appears Limited by the Substrate
}

\author{
Hao Zhang ${ }^{\star}$, David H. Lau ${ }^{\dagger}$, Iryna N. Shlapakova ${ }^{\dagger}$, Xin Zhao ${ }^{\ddagger}$, Peter Danilo ${ }^{\dagger}$, Richard B. \\ Robinson ${ }^{\dagger}$, Ira S. Cohen $§$, Dan Qu*, Zhiyun Xu*, and Michael R. Rosen ${ }^{\dagger}, \mathbb{I}$ \\ *Changhai Hospital, Second Military Medical University, Shanghai, China \\ tDepartment of Pharmacology, Center for Molecular Therapeutics, College of Physicians and \\ Surgeons, Columbia University, New York, NY, USA \\ ‡Division of Cardiology, First Affiliated Hospital of Soochow University, Su Zhou, China \\ §Department of Physiology \& Biophysics, Stony Brook University, Stony Brook, NY, USA \\ IDepartment of Pediatrics, College of Physicians and Surgeons, Columbia University, New York, \\ NY, USA
}

\begin{abstract}
Biological pacing has been proposed as a physiologic counterpart to electronic pacing, and the sinoatrial node (SAN) is the general standard for biological pacemakers. We tested the expression of SAN pacemaker cell activity when implanted autologously in the right ventricle (RV). We induced complete heart block and implanted electronic pacemakers in the RV of adult mongrel dogs. Autologous SAN cells isolated enzymatically were studied by patch clamp to confirm SAN identity. SAN cells $(400,000)$ were injected into the RV subepicardial free wall and dogs were monitored for 2 weeks. Pacemaker function was assessed by overdrive pacing and IV epinephrine challenge. SAN cells expressed a time-dependent inward current $\left(\mathrm{I}_{\mathrm{f}}\right)$ activating on hyperpolarization: density $=4.3 \pm 0.6 \mathrm{pA} / \mathrm{pF}$ at $-105 \mathrm{mV}$. Four of the six dogs demonstrated $>50 \%$ of beats originating from the implant site at $24 \mathrm{~h}$. Biological pacemaker rates on days 7-14 $=45-55 \mathrm{bpm}$ and post-overdrive escape times $=1.5-2.5 \mathrm{~s}$. Brisk catecholamine responsiveness occurred. Dogs implanted with autologous SAN cells manifest biological pacing properties dissimilar from those of the anatomic SAN. This highlights the importance of cell and substrate interaction in generating biological pacemaker function.
\end{abstract}

\section{Keywords}

Pacemaker current; Heart block; Cardiac pacing; Sinoatrial node

\section{INTRODUCTION}

Transvenous electronic pacing has been the standard for maintaining cardiac rhythm in the setting of complete heart block for over 50 years (29). Biological pacing has been explored

\footnotetext{
Copyright (C) 2011 Cognizant Comm. Corp

Address correspondence to Michael R. Rosen, M.D., Gustavus A. Pfeiffer Professor of Pharmacology, Professor of Pediatrics, Columbia University, 630 West 168 Street, PH7West-321, New York, NY, 10032, USA. Tel: 212-305-8754; Fax: 212-305-8351; mrr1@ columbia.edu or Zhiyun Xu, M.D., Director, Professor, Institute of Cardiothoracic Surgery, Changhai Hospital, Second Military Medical University, 168 Changhai Road, Shanghai, 200433, China. Tel: 13818178916; Fax: 86-021-65490979; zhiyunx@ hotmail.com.

The authors declare no conflict of interest.
} 
in an effort to further optimize pacemaker therapy (21). One approach, autologous transplantation to the ventricle of the sinoatrial node (SAN) or intact nodal tissue, was reported over 30 years ago, but with poor success [summarized in (16)]. In the late 1990s gene delivery of the $\beta_{2}$-adrenergic receptor was noted to augment the function of endogenous pacemaker tissues (8). Soon thereafter, implantation of fetal cells (22) or stem cells with pacemaker capability (10) was reported, as was gene delivery to modify the pacemaker potential using both viral $(15,20)$ and mesenchymal stem cell (19) platforms.

While proof of concept has been demonstrated for these therapies, none has achieved either the baseline performance or the diversity of autonomic responsiveness characteristic of the anatomic SAN (20). Two possible explanations are that the biological pacemakers implanted to date were inadequately designed to assume the characteristics of the SAN or that the ventricular myocardial substrate in which they were implanted is an environment inimical to robust expression of function of a pacemaker cell.

Therefore, we tested the hypothesis that isolated, autologous SAN cells implanted into the right ventricle (RV) would provide pacemaker function. We reasoned that if the approach were successful, the SAN cell might be a standard for developing autologous biological therapies. However, if it were inadequate, one might hypothesize that the properties of the substrate - the ventricle — are such that future strategies for pacemaker design would have to take the characteristics of the myocardial substrate into account more directly.

\section{MATERIALS AND METHODS}

\section{Intact Animal Studies}

All protocols were performed per American Physiological Society guidelines and were reviewed and approved by the Institutional Animal Care and Use Committees at Columbia University and at Changhai Hospital. Six adult male mongrel dogs $(22-25 \mathrm{~kg}$, Chestnut Ridge Kennels) were induced with thiopental (17 mg/kg, IV) and intubated. Dogs were mechanically ventilated and anesthesia was maintained with inhaled isoflurane (1.5-3.0\%). Under sterile techniques percutaneous radiofrequency ablation was performed to induce complete heart block and an electronic pacemaker (Discovery II, Guidant) was implanted with the pacing lead in the right ventricular apex and programmed at a demand rate of 35 bpm. A thoracotomy was performed through the right 4th intercostal space, the sinoatrial node identified visually and excised, and the resulting right atrial defect closed with nonabsorbable sutures.

Individual SAN cells were isolated by enzymatic digestion, as follows. The node was sectioned into $2 \times 2-\mathrm{mm}$ pieces and incubated $30 \mathrm{~min}$ at $37^{\circ} \mathrm{C}$ in oxygenated calcium-free Tyrode's solution with (in U/ml): 400 collagenase (Worthington), 0.6 protease (Sigma), and 4.6 elastase (Worthington). The solution was replaced by a high $\mathrm{K}^{+}$solution(in $\mathrm{mM}$ : Lglutamic acid 70, $\mathrm{KOH} 80, \mathrm{KCl} 20, \beta$-OH-butyric acid sodium salt $10, \mathrm{KH}_{2} \mathrm{PO}_{4} 10$, HEPES$\mathrm{KOH} 10$, taurine 10 , albumin $1 \mathrm{mg} / \mathrm{ml}, \mathrm{pH} 7.4$ ) and triturated $3 \mathrm{~min}$ to dissociate cells mechanically. The first fraction of SAN cells was isolated from the supernatant.

Enzymatic mechanical dissociation was performed two more times and all SAN fractions were filtered through a nylon mesh under centrifugation. Calcium concentration was equilibrated step-wise to $0.8 \mathrm{mM}$ in Tyrode's solution. SAN cells then were concentrated and suspended in a final volume of $1.5 \mathrm{ml}(0.5 \mathrm{ml}$ for patch clamp study, $1.0 \mathrm{ml}$ for implantation). A subset was studied via trypan blue exclusion.

The SAN cell isolation procedure invariably damages some cells and the yield of healthy cells can vary markedly from animal to animal. Further, multiple cellular morphologies are 
reported to exist in both rabbit and canine $\operatorname{SAN}(9,28)$ and some of these, such as so-called spider cells, can be difficult to distinguish from clusters of two or more spindle cells. Thus, to ensure the highest integrity of the single cell electrophysiological data, only spontaneously beating, clearly single, spindle-shaped cells were selected for biophysical study. Given the difficulty of definitively identifying the number of cells within clusters, we did not attempt to quantify what fraction of all cells met our selection criteria, but we estimate from separate experiments that more than $50 \%$ of the canine SAN cells are spindle shaped.

SAN cells $(3-5 \times 105)$ were injected into the right ventricle $(\mathrm{RV})$ subepicardial free wall. Six-lead electrocardiography (ECG) complexes were recorded during pacing from the injection site at the time of cell administration. These provided a basis for pace-mapping comparison with the ECG complexes recorded following recovery from surgery. The dogs were then followed via Holter monitoring over a 2-week period as well as by serial ECG recording. Function also was assessed by overdrive suppression and an IV epinephrine challenge at 14 days posttransplant, after which the experiment was terminated and the RV was examined for SAN cells.

\section{Patch Clamp Studies}

Patch clamp was used to confirm SAN cell identity and pacemaker function. Isolated SAN cells were placed in a heated $\left(35^{\circ} \mathrm{C}\right)$ bath perfused with $(\mathrm{mM}): 140 \mathrm{NaCl}, 5.4 \mathrm{KCl}, 2 \mathrm{CaCl}_{2}$, $1 \mathrm{MgCl}_{2}, 5$ HEPES, and 10 glucose (pH 7.4). Single, spindle-shaped, spontaneously beating cells were selected for study. Membrane potentials and currents were recorded in whole cell configuration using an Axopatch-1D amplifier (Axon Instruments) with pCLAMP software (version 8; Axon Instruments). Borosilicate glass pipettes were filled (mM): 90 aspartic acid, $10 \mathrm{NaCl}, 100 \mathrm{CsOH}, 30 \mathrm{CsCl}, 2 \mathrm{MgCl}_{2}, 5$ EGTA, $2 \mathrm{CaCl}_{2}, 10 \mathrm{HEPES}$ (pH 7.2).

Pipette resistance was 3-5 MOhms.

\section{Statistical Analysis}

Results are expressed as means $\pm \mathrm{SD}$. ANOVA was used for statistical analysis of the ventricular rhythms and a paired $t$-test was used to analyze epinephrine infusion data. A value of $p<0.05$ was considered to be significant.

\section{RESULTS \\ Isolated SAN Cells}

Pacemaker cells had a spindle- or spider-like shape with a single central nucleus (Fig. 1A). Over $80 \%$ of the cells were estimated to be viable, based on trypan blue exclusion. Eighteen cells were studied ( $3 / \mathrm{dog})$, and had beating rates of $90 \pm 17 \mathrm{bpm}$. Rhythm was stable during the recording procedure (Fig. 1B). The cells had a membrane capacitance of $41.6 \pm 9.5 \mathrm{pF}(n$ $=18)$ and expressed a typical time-dependent inward current $\left(\mathrm{I}_{\mathrm{f}}\right)$ activating on hyperpolarization up to $-105 \mathrm{mV}$ and deactivating during the following step to $15 \mathrm{mV}$ (Fig. $1 C)$. $\mathrm{I}_{\mathrm{f}}$ density was $4.3 \pm 0.6 \mathrm{pA} / \mathrm{pF}$ at $-105 \mathrm{mV}(n=18)$. Summary data of the currentvoltage relationship are shown in Figure 1D.

\section{Intact Animal Studies}

Ventricular rhythms stabilized fully within 3 days after surgery and four of the six dogs showed effective biological pacing during the study period (Fig. 2). This was evidenced as more than $50 \%$ of ventricular complexes that pace-mapped to the injection site $24 \mathrm{~h}$ after cell administration (Fig. 3). Summary data for these four dogs following stabilization of rhythm are shown in Figure 2. Note that the percent of beats pace-mapped to the injection site declined over 14 days while the percent of electronically stimulated beats increased. 
Escape rates were over $60 \mathrm{bpm}$ on day 4 and declined to $48 \mathrm{bpm}$ by day 14. Escape intervals ranged from 1.5 to $3.5 \mathrm{~s}$.

On day 14 animals rested quietly on the table for $30 \mathrm{~min}$ with their electronic pacemakers turned off. Epinephrine $1.5 \mu \mathrm{g} / \mathrm{kg} / \mathrm{min}$ was then infused for $10 \mathrm{~min}$. The heart rates were increased by epinephrine from $45 \pm 4$ to $63 \pm 6 \mathrm{bpm}(p<0.05)$. Animals were then sacrificed. Disaggregated SAN cells from the myocardial implantation site were identified by microscopic examination (see Fig. 1) and noted to be beating spontaneously in vitro.

\section{DISCUSSION}

Modern understanding of the origin of the heartbeat (4) is traceable to Keith and Flack's 1907 publication identifying the anatomic sinoatrial node (11) and Lewis et al.'s 1910 demonstration that the SA node is the source of the normal heartbeat (13). An extensive literature has since demonstrated propagation of waveforms from the SA node, the action potentials of the SA node and of secondary pacemakers, and the ion currents and channels responsible for primary and secondary pacemaker function $(2,3,6,7,12)$. Paralleling discovery regarding normal SA nodal function has been an appreciation of the pathology of the node and the atrioventricular (AV) conducting system. A major breakthrough in masstreating AV block came about 50 years ago, and since then electronic pacing has been the state of the art treatment for complete heart block and a variety of other arrhythmias (29). Although much improved over this period and an excellent palliative electronic pacing remains beset by problems with lead fracture and extraction, power pack replacement, nominal autonomic responsiveness, interference, incompatibility with the growing and developing heart, ventricular dyssynchrony, and cardiac failure $(21,29)$.

About 10 years ago, we and others began reporting "biological pacing," attempting to build a pacemaker via the tools of gene and cell therapy [reviewed in (21)]. A biological pacemaker is envisioned to be of lifelong durability, autonomically responsive, implantable at sites that will optimize cardiac output for individual patients, adaptable to growth and development, and unencumbered with risks of neoplasia, infection, interference, lead fracture, or cardiac failure (21). Although this is a tall order, the availability of an electronic palliative makes the search for a biological replacement one that can seek optimization before advancement to clinical use.

In this initial decade of exploration proof of concept has been provided using a variety of approaches to either increase inward current or decrease repolarizing current as means for creating a pacemaker potential $(5,10,14,15,17,18,20,24)$. Over this interval the use of variants on the hyperpolarization-activated cyclic nucleotide gated $(\mathrm{HCN})$ channel family of pacemaker genes has come to the fore. However, there have been significant problems as well, manifested as inadequate outcome at the level of both biological pacemaker function and durability. For example, we have shown that implanting adult human mesenchymal stem cells carrying the pacemaker gene HCN2 into the LV anterior wall of dogs with complete heart block results in resting idioventricular rates of $\sim 50 \mathrm{bpm}$, while adenoviral constructs of $\mathrm{HCN} 2$ implanted into the left bundle branch region manifested basal idioventricular rates of 50-60 bpm $(5,17)$. The rhythms are catecholamine responsive. Our present results in dogs implanted with autologous SAN cells in the RV free wall show that the ventricular pacing rates and catecholamine responsiveness are comparable to those of the previously reported biological pacemakers.

The similarities in function of $\mathrm{HCN} 2$ implanted as a viral construct in specialized conducting system or via a human mesenchymal stem cells (hMSC) platform in ventricular myocardium and SAN cells implanted in myocardium is of interest because of the very 
different properties of the administered pacemaker cells. Implanting HCN2 into Purkinje fibers adds a diastolic depolarizing current to a cell type that already has this current as well as the complete machinery to generate an action potential. The array of Purkinje fiber ion currents includes a low $\mathrm{I}_{\mathrm{K} 1}$ ensuring that only a small hyperpolarizing current will counteract the depolarizing effects of $\mathrm{I}_{\mathrm{HCN} 2}$. In contrast, implanting hMSCs loaded with $\mathrm{HCN} 2$ into myocardium has been shown to require both the formation of functioning gap junctions among hMSCs and adjacent myocytes and the ability of the $\mathrm{I}_{\mathrm{HCN} 2}$ generated to counteract the hyperpolarizing effects of the robust $\mathrm{I}_{\mathrm{K} 1}$ of muscle $(25,26)$.

SAN cells have a pacemaker current initiated by HCN4 and HCN1 and their pacemaker activity is facilitated by a low $\mathrm{I}_{\mathrm{K} 1}$ (21). That their pacemaker function is no better or worse than that of the hMSC-based pacemaker highlights the important influence of substrate on pacemaker function. Among the differences between hMSC-based pacemaker cells and SAN cells are: the SA node myocyte paces on its own, while the hMSC pacemaker is a twocell functional syncytium requiring gap junctional coupling between hMSC and myocyte; the SA node action potential upstroke is generated by L-type calcium current whereas the hMSC pacemaker upstroke employs the sodium current of the myocyte to which it is coupled; the SA node myocyte has little or no $\mathrm{I}_{\mathrm{K} 1}$, the hMSC-myocyte pair has more, with the $\mathrm{I}_{\mathrm{K} 1}$ magnitude depending on myocyte properties at the placement site in the heart; the maximum diastolic potential (MDP) in sinus node myocytes is roughly $-60 \mathrm{mV}$; that for the myocyte component of the hMSC pacemaker can be negative to $-70 \mathrm{mV}$; the SA node employs a calcium clock as well as $\mathrm{I}_{\mathrm{f}}(3,12)$ while the role of the calcium clock is uncertain in the hMSC-based pacemaker. Finally, a key determinant of primary pacemaker activity is the isolation of the SA node from the atrium by limited gap junctional coupling $(23,27)$. However the mechanism by which the coupling level determines primary pacemaker function is not well understood.

Despite numerous studies on biological pacemakers there has been little investment in understanding how the electrical properties of target cells can influence the behavior of biological pacemakers. Certainly investigations and assumptions have been made regarding the unique anatomy of the SA node and its placement with regard to the perinodal fibers and activation pathways of the right atrium $(1,4)$. Although we did not implant SAN cells in the left atrium as an alternative target site, given the low atrial $\mathrm{I}_{\mathrm{K} 1}$ we would expect a more rapid pace-maker rate in atrium than was found in the ventricle.

In sum, the design of biological pacemakers to date has focused on the pacemaking unit as a generator of electrical activity. However, this approach should be modified to take into account the substrate at the implantation site, reflecting regional variability. The SAN cell that has a set of ion currents and gap junctional proteins that support its robust function in the right atrial anatomic setting loses much of its range of activity when placed in the environment of the ventricle. Lessons learned from studying the properties of the substrate into which we introduce biological pacemakers will likely improve our ability to tailor the next generation of these pacemakers to function optimally for implantation in selected regions of the heart.

\section{Limitations}

Cell injection can be associated with significant cell mortality, and the rate of survival and local confinement of implanted stem cells at an injection site is low. Hence, we cannot exclude that a critical SA node cell and electrical mass for optimal pacing is present. We previously have performed studies of cell number versus pacing capability for HCN2-loaded hMSCs (17) and the identification of cell number for the present study was based on the numbers of cells found to be optimal. Interestingly, the pacemaker characteristics of the SA node cells in the present experiments approximated those of $\mathrm{HCN} 2$ pacemakers delivered 
either via hMSCs or viral vectors (5,17-19). Nonetheless, "dose ranging" of SA node cells would be a good idea for the future. Although we present no sham-injected animals as controls here, we have previously reported on these in detail: their pacemaker rates are in the $40 \mathrm{bpm}$ range $(5,17-19)$, clearly below that of the SA node cell or hMSC-derived or virally delivered biological pacemakers.

\section{Acknowledgments}

The authors thank Dr. Lev Protas for his advice and assistance in performing certain of the experiments, and acknowledge with gratitude the contribution of Ms. Eileen Franey to the preparation of this manuscript. This work was supported by United States Public Health Service-National Heart Lung Blood Institutes grant HL-28958. Additional personnel and research support came from National Science Foundation of China grants 30672075 and 30700157 and from Science and Technology Commission of Shanghai Municipality grant 09410705500.

\section{References}

1. Anderson R, Ho S. The architecture of the sinus node, the atrioventricular conduction axis and the intermodal atrial myocardium. J Cardiovasc Electrophysiol. 1998; 9:1233-1248. [PubMed: 9835269]

2. Barbuti A, DiFrancesco D. Control of cardiac rate by "funny" channels in health and disease. Ann NY Acad Sci. 2008; 1123:213-223. [PubMed: 18375593]

3. Bogdanov KY, Maltsev VA, Vinogradova TM, Lyashkov AE, Spurgeon HA, Stern MD, Lakatta EG. Membrane potential fluctuations resulting from sub-membrane $\mathrm{Ca}^{2+}$ releases in rabbit sinoatrial nodal cells impart an exponential phase to the late diastolic depolarization that controls their chronotropic state. Circ Res. 2006; 99:979-987. [PubMed: 17008599]

4. Brooks, CMcC; Lu, HH. The sinoatrial pacemaker of the heart. Fort Lauderdale, FL: Charles C. Thomas; 1972.

5. Bucchi A, Plotnikov AN, Shlapakova I, Danilo P Jr, Kryukova Y, Qu J, Lu Z, Liu H, Pan Z, Potapova I, KenKnight B, Girouard S, Cohen IS, Brink PR, Robinson RB, Rosen MR. Wild-type and mutant HCN channels in a tandem biological-electronic cardiac pacemaker. Circulation. 2006; 114:992-999. [PubMed: 16923750]

6. Chandler NJ, Greener ID, Tellez JO, Inada S, Musa H, Molenaar P, Difrancesco D, Baruscotti M, Longhi R, Anderson RH, Billeter R, Sharma V, Sigg DC, Boyett MR, Dobrzynski H. Molecular architecture of the human sinus node: Insights into the function of the cardiac pacemaker. Circulation. 2009; 119:1562-1575. [PubMed: 19289639]

7. DiFrancesco D. A study of the ionic nature of the pacemaker current in calf Purkinje fibres. J Physiol. 1981; 314:377-393. [PubMed: 6273534]

8. Edelberg JM, Huang DT, Josephson ME, Rosenberg RD. Molecular enhancement of porcine cardiac chronotropy. Heart. 2001; 86:559-562. [PubMed: 11602553]

9. Gao Z, Chen B, Joiner ML, Wu Y, Guan X, Koval OM, Chaudhary AK, Cunha SR, Mohler PJ, Martins JB, Song LS, Anderson MEI. f and SR Ca ${ }^{2+}$ release both contribute to pacemaker activity in canine sinoatrial node cells. J Mol Cell Cardiol. 2010; 49:33-40. [PubMed: 20380837]

10. Kehat I, Khimovich L, Caspi O, Gepstein A, Shofti R, Arbel G, Huber I, Satin J, Itskovitz-Eldor J, Gepstein L. Electromechanical integration of cardiomyo-cytes derived from human embryonic stem cells. Nat Biotechnol. 2004; 22:1282-1289. [PubMed: 15448703]

11. Keith A, Flack MW. The form and nature of the muscular connections between the primary divisions of the vertebrate heart. J Anat Physiol. 1907; 41:172-189. [PubMed: 17232727]

12. Lakatta EG, Maltsev VA, Vinogradova TM. A coupled SYSTEM of intracellular intracellular $\mathrm{Ca}^{2+}$ clocks and surface membrane voltage clocks controls the timekeeping mechanism of the heart's pacemaker. Circ Res. 2010; 106:659-673. [PubMed: 20203315]

13. Lewis T, Oppenheimer BS, Oppenheimer A. The site of origin of the mammalian heartbeat; the pacemaker in the dog. Heart. 1910; 2:147-169.

14. Lieu DK, Chan YC, Lau CP, Tse HF, Siu CW, Li RA. Overexpression of HCN-encoded pacemaker current silences bioartificial pacemakers. Heart Rhythm. 2008; 5:1310-1317. [PubMed: 18693074] 
15. Miake J, Marbán E, Nuss HB. Gene therapy: Biological pacemaker created by gene transfer. Nature. 2002; 419:132-133. [PubMed: 12226654]

16. Morishita Y, Poirier RA, Rohner RF. Sinoatrial node transplantation in the dog. Vasc Endovasc Surg. 1981; 15:388-393.

17. Plotnikov AN, Shlapakova IN, Szabolcs MJ, Danilo P Jr, Lorell BH, Potapova IA, Lu Z, Rosen AB, Mathias RT, Brink PR, Robinson RB, Cohen IS, Rosen MR. Xenografted adult human mesenchy- mal stem cells provide a platform for sustained biological pacemaker function in canine heart. Circulation. 2007; 116:706-713. [PubMed: 17646577]

18. Plotnikov AN, Sosunov EA, Qu J, Shlapakova IN, Anyukhovsky EP, Liu L, Janse MJ, Brink PR, Cohen IS, Robinson RB, Danilo P Jr, Rosen MR. A biological pacemaker implanted in the canine left bundle branch provides ventricular escape rhythms having physiologically acceptable rates. Circulation. 2004; 109:506-512. [PubMed: 14734518]

19. Potapova I, Plotnikov A, Lu Z, Danilo P Jr, Valiunas V, Qu J, Doronin S, Zuckerman J, Shlapakova IN, Gao J, Pan Z, Herron AJ, Robinson RB, Brink PR, Rosen MR, Cohen IS. Human mesenchymal stem cell as a gene delivery system to create cardiac pacemakers. Circ Res. 2004; 94:841-959.

20. Qu J, Plotnikov AN, Danilo P Jr, Shlapakova I, Cohen IS, Robinson RB, Rosen MR. Expression and function of a biological pacemaker in canine heart. Circulation. 2003; 107:1106-1109. [PubMed: 12615786]

21. Rosen MR, Brink PR, Cohen IS, Robinson RB. Cardiac pacing: From biological to electronic .... . to bio- logical? Circ Arrhythmia Electrophysiol. 2008; 1:54-61.

22. Ruhparwar A, Tebbenjohanns J, Niehaus M, Mengel M, Irtel T, Kofidis T, Pichlmaier AM, Haverich A. Transplanted fetal cardiomyocytes as cardiac pacemaker. Eur J Cardiothorac Surg. 2002; 21:853-857. [PubMed: 12062274]

23. Severs NJ, Dupont E, Thomas N, Kaba R, Rothery S, Jain R, Sharpey K, Fry CH. Alterations in cardiac connexin expression in cardiomyopathies. Adv Cardiol. 2006; 42:228-242. [PubMed: 16646594]

24. Tse HF, Xue T, Lau CP, Siu CW, Wang K, Zhang QY, Tomaselli GF, Akar FG, Li RA. Bioartificial sinus node constructed via in vivo gene transfer of an engineered pacemaker $\mathrm{HCN}$ channel reduces the dependence on electronic pacemaker in a sick-sinus syndrome model. Circulation. 2006; 114:1000-1011. [PubMed: 16923751]

25. Valiunas V, Doronin S, Valiuniene L, Potapova I, Zuckerman J, Walcott B, Robinson RB, Rosen MR, Brink PR, Cohen IS. Human mesenchymal stem cells make cardiac connexins and form functional gap junctions. J Physiol. 2004; 555:617-626. [PubMed: 14766937]

26. Valiunas V, Kanaporis G, Valiuniene L, Gordon C, Wang HZ, Li L, Robinson RB, Rosen MR, Cohen IS, Brink PR. Coupling an HCN2-expressing cell to a myocyte creates a two-cell pacing unit. J Physiol. 2009; 587(Pt. 21):5211-5226. [PubMed: 19736302]

27. Van Veen TAB, van Rijen HWM, Opthof T. Cardiac gap junction channels: Modulation of expression and channel properties. Cardiovasc Res. 2001; 51:217-229. [PubMed: 11470461]

28. Wu J, Schuessler RB, Rodefeld MD, Saffitz JE, Boineau JP. Morphological and membrane characteristics of spider and spindle cells isolated from rabbit sinus node. Am J Physiol Heart Circ Physiol. 2001; 280:H1232-H1240. [PubMed: 11179068]

29. Zivin, A.; Mehra, R.; Bardy, GH. Cardiac pacemakers. In: Spooner, PM.; Rosen, MR., editors. Foundations of cardiac arrhythmias. New York: Marcel Dekker Inc; 2001. p. 571-598. 


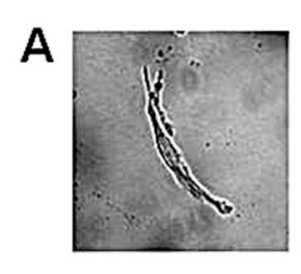

C

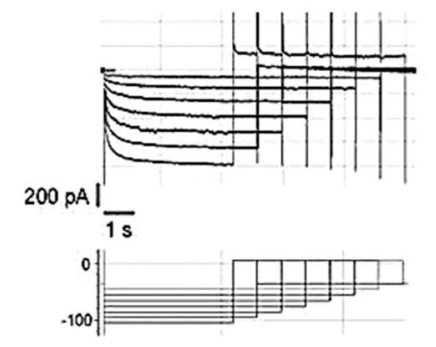

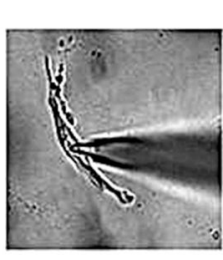

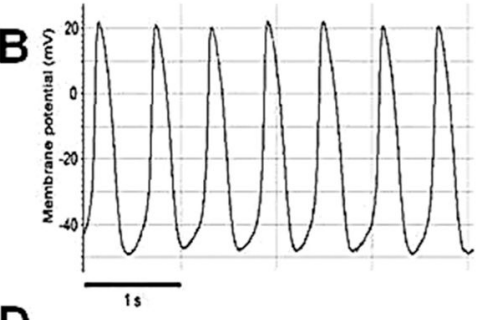

D

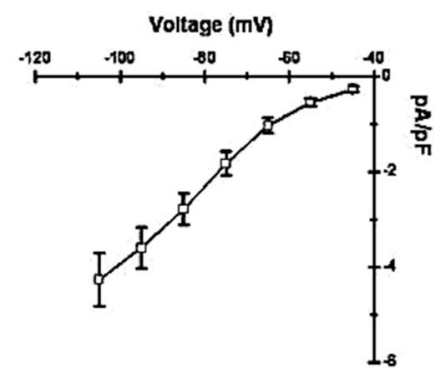

Figure 1.

(A) Dissociated sinoatrial node (SAN) cell in recording chamber before and during patch electrode impalement. Dissociated SAN cells were spindle shaped and more than $80 \%$ exhibited spontaneous rhythms in calcium-free enzyme solution. Only single dissociated SAN cells with contractile activity were selected for microelectrode study. (B) Dissociated SAN cells manifest spontaneous action potentials. (C) Representative records from a dissociated SAN cell during the voltage clamp protocol. (D) Summary data: SAN cells exhibit robust $\mathrm{I}_{\mathrm{f}}$ (density $4.3 \pm 0.6 \mathrm{pA} / \mathrm{pF}$ at $-105 \mathrm{mV}$ ). 

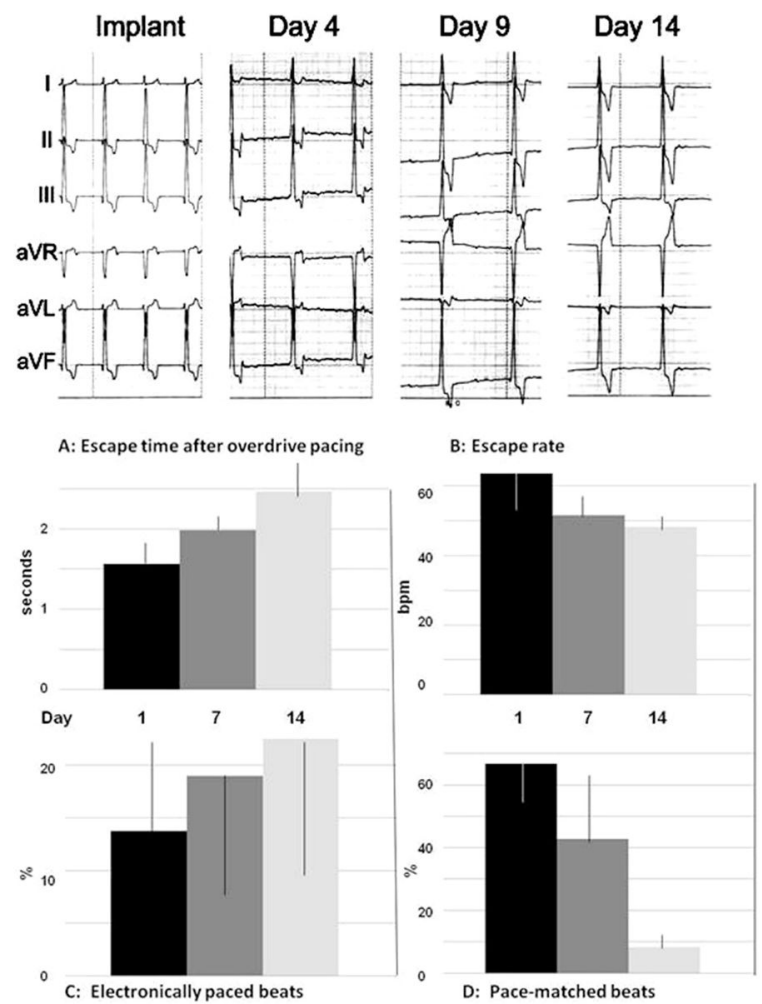

Figure 2.

Upper panel: Representative surface electrocardiography (ECGs) from a dog following autologous SAN cells transplant. The "Implant" ECG shows the pace-mapped surface ECG obtained by electronically pacing the implant site during surgery. ECGs were then recorded over a 14-day period. Shown are ECGs recorded on day 4, 9, and 14. Note that the QRS axis and configuration are similar to the QRS recorded during surgery suggesting the ventricular pacemaker activity is originating from the SAN cells' implant site. Paper speed $=25 \mathrm{~mm} / \mathrm{s}$; $1 \mathrm{~cm}=1 \mathrm{mV}$. Lower panels: Escape times after overdrive pacing (A), escape rates (B), percent of electronically paced beats $(\mathrm{C})$, and percent of beats that pace-mapped to the injection site (D) for the 4 dogs showing $>50 \%$ of beats mapping to the injection site on days $1-2$. Shown here are data from days 1,7 , and 14 as means \pm SD. ANOVA shows no differences across days. See text for discussion. 

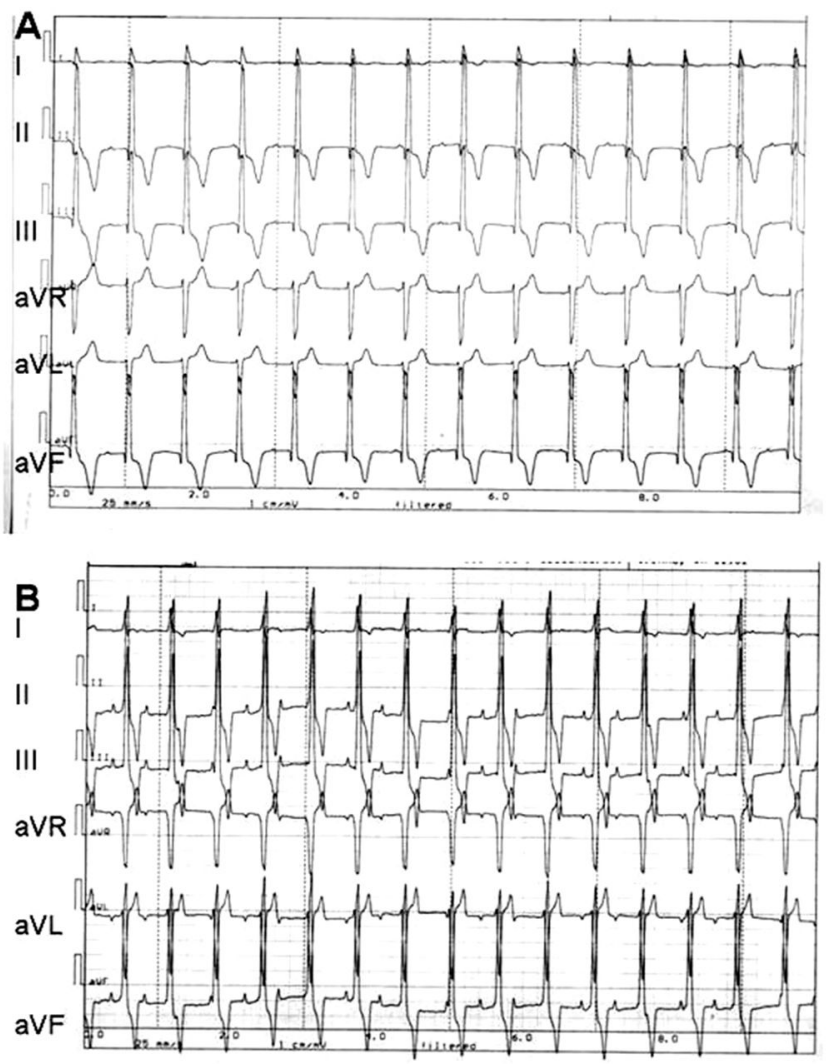

Figure 3.

Pace-mapping data from one dog using six-lead ECG. (A) Recording during electronic pacing using a bipolar electrode placed epicardially at the site of cell administration. (B) Recording 2 days later from the awake animal of biological pacemaker-induced rhythm. Note comparability of complexes in (A) and (B). 